\title{
EL SUBLEGADO EN EL DERECHO CIVIL CHILENO*
}

\author{
SUBLEGACY IN CHILEAN CIVIL LAW
}

\begin{abstract}
ALEJANDRO GUZMÁN BRITO**
RESUMEN: La doctrina denomina "sublegado" a la figura consistente en imponer el pago de un legado a otro legatario el testador. Se critica la denominación, que no corresponde al esquema que rige en la generalidad de los negocios designado con el prefijo "sub-", como subarrendamiento, submandato y otros, porque en la relación legataria (o en el cuasicontrato que se forma por la aceptación de un legado), no se da que una de sus partes vuelva a serlo con un tercero en otro negocio del mismo carácter que el primer legado, o sea, en otro legado, sobre el mismo objeto del primero. Pero, independientemente del nombre que quiera escogerse, se trata de examinar el régimen de la figura consistente en que alguien legue a otro la cosa que fue o haya de ser legada a él mismo, que, en todo caso, admite mejor la denominación de "sublegado". Aunque esta figura no aparece regulada por el Código Civil, a la luz principalmente de sus artículos 1107 y 1108 encuentra un régimen positivo aplicable, cuyo desarrollo es el tema del artículo.
\end{abstract}

Palabras clave: legado, sublegado.

ABSTRACT: The doctrine calls "sublegacy" the figure of imposing the payment of a legacy to another legatee of the testator. It criticizes the name, which does not match the schema that governs the majority of businesses that are designated the prefix "-sub", such as a sublease, submandate, and others, because in the legatory relation (or quasi-contracts formed because of the acceptance a legacy), one of the parts is not a part again with a third in another business similar to the first legacy, or bequest to another on the same subject of the first. But whatever the chosen name, one must examine the scheme of the figure whereby someone bequeath to someone else the thing that was or is to be bequeathed to him, which in any case, best admits the title of "sublegacy". Although this figure is not regulated by the Civil Code, in the light of articles 1107 and 1108 it has found a positive regime applicable, the development of which is the subject of the article.

Key words: legacy, sublegacy.

1. El artículo 1360 CC. legitima al testador para imponer a algún legatario suyo el pago de cierto legado previamente dispuesto por él mismo a favor de otra persona en su testamento; caso en el cual el legatario gravado está obligado a responder solo hasta

* Este trabajo hace parte del proyecto Fondecyt $\mathrm{N}^{\circ}$ 1070432, de 2007.

** Licenciado en Ciencias Jurídicas y Sociales, Pontificia Universidad Católica de Valparaíso. Doctor en Derecho por la Universidad de Navarra, España. Catedrático de Derecho romano de la Facultad de Derecho de la Pontificia Universidad Católica de Valparaíso. Dirección postal: Facultad de Derecho, Pontificia Universidad Católica de Valparaíso, Avenida Brasil 2950, Valparaíso, Chile. Correo electrónico: aguzman@ucv.cl 
concurrencia del provecho que le reporte su propia asignación (artículo 1364 CC.) ${ }^{1}$. Tal es una de las posibilidades de sustitución de la regla general supletoria, contenida en la misma norma antes citada, en orden a que el pago de los legados queda a cargo de los herederos en su conjunto y a prorrata de sus cuotas en la sucesión ${ }^{2}$. Esta figura de un legado cuyo pago queda puesto a cargo de otro legatario por el testador es denominada "sublegado" por la doctrina chilena más moderna, quizá debido a una influencia de la civilística italiana ${ }^{3}$. Tal denominación es incorrecta.

En general, la imposición de denominaciones técnico-jurídicas con recurso a un sustantivo designador de cierto acto o contrato y al prefijo "sub-" 4 queda (o debería quedar) reservada para designar al acto o contrato que recae sobre el objeto de otro de su mismo tipo, anteriormente celebrado por una de las partes del nuevo acto o contrato, que ella celebra, pero ahora con un tercero. La relación general que entonces se genera entre los dos actos o contratos es, precisamente, de subordinación del subacto o subcontrato al acto o contrato principal, en cuanto el destino de aquel depende del destino de este.

Tal es, por ejemplo, el caso del contrato de arrendamiento de cierta cosa, cuyo arrendador la tenía recibida antes en arrendamiento y ahora la concede bajo el mismo respecto a un tercero. Lo propio puede acaecer en el contrato de arrendamiento para la confección de una obra material, si el artífice o arrendatario la da total o parcialmente en arrendamiento a otro artífice; en el arrendamiento de servicios inmateriales, si el

\footnotetext{
${ }^{1}$ En la concepción del Código (artículo 1437) se forma el cuasicontrato de aceptación de un legado. Esta construcción debe entenderse así: como el legatario que acepta su asignación al punto queda obligado a cumplir aquellos legados cuyo pago le impuso el testador (artículo 1360 CC.), y es evidente que tal obligación no nace de algún contrato que el legatario haya celebrado, ni con el legatario ni, por cierto, con el testador, entonces queda obligado por un cuasicontrato o hecho lícito no convencional consistente en su aceptación, que precisamente genera obligaciones. Se entiende que ello es solo cuando el legado es fuente de obligaciones. El legado de efecto real, como el que la doctrina llama "de especie", no forma cuasicontrato por su aceptación, porque no hay obligaciones entremedio. El artículo 1437 CC. también extiende la calidad de cuasicontrato a la aceptación de una herencia, en cuanto el heredero empieza a quedar obligado a pagar los legados (artículo 1360 CC.), sin que haya contratado ni con el testador ni con el legatario. En consecuencia, que el Código considere cuasicontrato a la aceptación de una herencia no es por la carga de las deudas hereditarias que pesa sobre el heredero. Lo dice expresamente BELLO, Andrés (1981), lib. III, tít. 280 [(1981), pp. 162-163]: "No cuasicontrae [el heredero] con los acreedores [hereditarios], porque con respecto a estos no hace más que sustituirse al difunto". Pese a la dicción del artículo 1437 CC., algunos sostienen que la aceptación de una herencia o legado no es cuasicontrato, con un argumento exegético: la norma no dice: “y en todos los demás cuasicontratos", mas solo "y en todos los cuasicontratos"; por ende, la aceptación no es cuasicontrato y solo va equiparada a él (?). Véase: ABELIUK MANASEVICH (1993) I, núm. 186, p. 154, quien sigue lo que sostenía Manuel Somarriva.

2 El testador también puede alterar esta regla si impone el pago de un legado a determinado heredero de entre varios (artículo 1360 CC.).

3 Domínguez Benavente y Domínguez Águila (1998) II, núm. 756, pp. 742. Estos autores parecen ser los introductores de la terminología: véase, Domínguez BEnAVENTE y Domínguez ÁGUILA (1998) núm. 756.1, p. 743, la cita de Messineo, quien habla de "sublegado". Les siguen: RodríGUEZ GREZ (2002) I, pp. 227-228; y ElORRIAGA DE BONIS (2005) núm. 396, pp. 334-335. La doctrina más antigua, en cambio, desconocía la denominación: Claro Solar (1982) XVII, V, núm. 2758, pp. 324-325; MEZA Barros (2007) núm. 794, p. 198; SOMARRIVA UNDURRAGA (2005) II, núm. 853, p. 676.

"Se podría hablar genéricamente de "subacto", como se habla de "subcontrato".
} 
obligado a prestarlos subcontrata con un tercero para que los preste él; y en el arrendamiento de transporte, si el acarreador subcontrata con un tercero el transporte ${ }^{5}$. Puede acaecer también en el mandato, cuando el mandatario encarga a un tercero la ejecución de la gestión que le había sido mandada a él por otro; o en el depósito, comodato o prenda de cierta cosa celebrados por su ya depositario, comodatario o pignoratario con un tercero sobre la misma cosa previamente recibido bajo esos títulos por él.

El Código Civil no conoce la figura del subcontrato como general y ni siquiera la expresión; pero sí ciertas especies, que no define ni describe, empero, y tampoco denomina, salvo en un caso, todas las cuales suponen la noción, como es el caso del subarrendamiento de $\operatorname{cosas}^{6}$ y de subarrendamiento de construcción ${ }^{7}$. También conoce el submandato, que denomina, sin embargo, "delegación" 8 . Asimismo, aunque sin designarla, conoce una subsociedad?. Algunos artículos suponen una "subfianza"10; pero ellos se refieren a la fianza dada por alguien para garantizar la obligación de otro ya fiador. Ahora bien, esta fianza de una fianza mejor se denominaría "sobrefianza". Por las razones que ofrecimos precedentemente, una auténtica subfianza no puede existir, porque no tiene sentido decir que el objeto de la fianza asumida por alguien es hecho él mismo objeto de otra fianza otorgada o contraída por él con un tercero. El Código de Comercio habla de "subarrendar" $\operatorname{cosas}^{11}$ y describe el "subfletamento" con esta denominación 12 . Sin denominarlo, conoce un subtransporte ${ }^{13}$. La Ley No 20.123 (DO. de 16 de octubre de 2006) regula el trabajo "en régimen de subcontratación", así que podemos hablar de subcontrato de trabajo, etcétera ${ }^{14}$.

2. En tales circunstancias, el vocablo "sublegado", aplicado al legado cuyo pago queda impuesto a cierto legatario suyo por el testador, no está correctamente atribuido a la figura, porque, si bien haya dos actos del mismo tipo, o sea, dos legados, estos recaen en objetos diferentes y fueron dispuestos por un mismo testador; no, pues, sobre un mismo objeto y por dos personas diferentes, la segunda de las cuales es parte de ambos legados. Esto último obliga a explicar en qué sentido puede alguien ser "parte" de un legado.

\footnotetext{
${ }^{5}$ En este contrato, la posibilidad del subcontrato está incluso prevista en su definición por el artículo 2013 CC.: "[...] es un contrato en que una parte se compromete [...] a transportar o a hacer transportar una persona $o$ cosa de un paraje a otro".

${ }^{6}$ Véanse los artículos 1946 (subarrendar y subarrendatario), 1947 inciso $4^{\circ}$ y 1963 (subarrendatario) y 1973 CC. (subarrendar).

7 Artículo 2003 No 5 CC.

${ }^{8}$ Véanse los artículos 2136 y 2137 CC. Cfr. los artículos 2135 (delegar y delegado) y 2136, 2137 y 2138

CC. (delegado).

${ }^{9}$ Artículo 2088 CC.

${ }^{10}$ Véanse los artículos 2360, 2366, 2367 inciso $3^{\circ}, 2380$ y 2383 CC.: en todos los casos se habla de "subfiador".

${ }^{11}$ Artículo 3 C. de C.: ánimo de subarrendar cosas.

${ }^{12}$ Artículo 932 C. de C.; cfr. sus artículos 862 y 967.

${ }^{13}$ Artículo 168 C. de C.

14 Sobre el subcontrato en general, véase: López SANTA MARía (2005) I, núm. 36, pp. 222-227, con literatura.
} 
Porque es cierto que los legados no tienen "partes", sino un único autor, el testador, cuya sola declaración de voluntad, en la forma testamentaria legal, es bastante para perfeccionarlos. El tercero beneficiario del legado, vale decir, el legatario, no es parte de aquel, sino solo eso: un tercero; así que resultare inane la crítica de no haber en el llamado "sublegado" por la doctrina una parte que también lo sea de un legado diferente, porque ninguno de ambos legados tiene partes.

Pero también es cierto esto otro: que el tercero beneficiario de un legado, o legatario, aunque no es parte del acto jurídico así denominado, que no tiene partes, desde que acepta la asignación, sin embargo, se hace parte del legado, tomado este término en su acepción no de acto sino de efecto, o, si se prefiere, se hace parte de la relación jurídica legataria que entonces se forma ${ }^{15}$. Por lo demás, en la concepción del Código, la aceptación del legatario forma un cuasicontrato (artículo 1437 CC.); y como no es impropio decir que los cuasicontratos sí tienen "partes", he ahí que entonces no resulta incorrecto afirmar que el legatario, con su aceptación, se hace parte del cuasicontrato que entonces se forma.

Para que haya verdadero sublegado, pues, el legatario que es parte en el sentido dicho, o mejor, por las razones que diremos, que va a serlo cuando acepte, debe ser también el autor de otro legado, precisamente del sublegado. Tal estructura queda muy alejada de la figura consistente en que un mismo testador disponga dos legados sobre objetos diferentes a favor de personas distintas, y grave con el cumplimiento de uno de ellos a alguno de los dos legatarios. En tal hipótesis no existen las conexiones internas y estructurales de objeto y personas que se dan en la figura primeramente descrita, ni, desde luego, subordinación de un legado a otro. Aplicado a un contrato el esquema que se tiene en el llamado "sublegado" por la doctrina, equivaldría a que alguien, por ejemplo, arrendara cierta cosa a uno y otra cosa a un arrendatario diferente, lo cual no determina, por cierto, que haya un subarrendamiento dependiente de un arrendamiento, sino dos arrendamientos independientes entre sí. Esto solo ya impide que el llamado "sublegado" por la doctrina pueda ingresar en la noción general de subacto.

Ahora bien, que el cumplimiento de uno de los legados grave a otro legatario, tal es una circunstancia del todo extrínseca a la estructura exigible para que haya un subacto, pues pertenece a la fase de ejecución de un acto ya perfecto. Tal conexión puramente exterior entre los dos legados, pues, no es bastante para entender haber un sublegado.

3. Así miradas las cosas, se podría hablar con más precisión de "sublegado" cuando alguien lega a otro una cosa actualmente ajena que le fue o ha de serle legada a él. Sintéticamente, pues, el sublegado es un legado de la cosa ajena legada; tal como acaece en el siguiente ejemplo, supuesto que Ticio haya dispuesto así en su testamento: "Lego el fundo Corneliano a Cayo", cuando después, pero antes de adquirir aquel legado, Cayo, en su propio testamento, dispone de esta otra manera: "Lego a Mevio el fundo Corneliano que Ticio me tiene legado (o me legó)”. Ahora la figura consiste en el legado

15 De hecho, el Código Civil lo considera sucesor a título singular (artículos 951 inciso $3^{\circ}$, 953 y 954 CC.). 
que el legatario de un objeto dispuesto en el testamento de otro a su favor, dispone en el suyo a favor de un tercero. Ella, mutatis mutandis, sí equivale al arrendamiento del objeto arrendado por su arrendatario a un tercero; o del depósito del objeto depositado por su depositario a un tercero; o del mandato de la gestión mandado por su mandatario a un tercero, etcétera. El paralelismo es perfecto y entonces queda consentido denominar "sublegado" a la segunda disposición, a la de Cayo en el ejemplo.

Pero, independientemente del nombre que quiera imponerse a la figura antes descrita, hay un hecho cierto: que tal figura puede darse, desde luego en teoría, pero también en la práctica. Por consiguiente, menester es examinar su corrección dogmática y legal y sus efectos. A ello dedicamos el presente artículo. Debe advertirse, con todo, que por economía de lenguaje y porque parece apropiado, según las explicaciones antes dadas, emplearemos la voz "sublegado" para referirnos a ella, tal vez en espera de un nombre mejor.

La figura, tal cual se la ha descrito, no está prevista en el Código Civil. Pero encuentra ajustada inserción en su sistema, porque, de darse en los hechos, el régimen aplicable proviene muy naturalmente de la combinación de los artículos 1107 y 1108 CC., como veremos. Menester es advertir que en nuestros análisis nos limitaremos al legado de especie de efecto real, para no complicar aquellos.

4. Hemos dicho que el sublegado tiene que recaer sobre cosa ajena. Tal es su primer requisito. Esto significa que debe ser dispuesto antes de que quien asigna la cosa en sublegado la haya adquirido merced al legado de otro, que llamaremos principal. Si acaece lo contrario, vale decir, que se legue una especie recibida a título de legado ya aceptado y, por ende, después que el testador la adquirió, entonces la asignación no es un sublegado, sino un legado ordinario que nada de especial ofrece a consideración, porque no se diferencia del que disponga el testador sobre cualquier otra cosa que le pertenezca, respecto de las cuales nunca interesa el modo con que la adquirió. Da lo mismo, en efecto, que el testador que lega una especie propia, en algún momento anterior se haya hecho su dueño entre vivos por tradición fundada en cualquier título traslaticio, o por causa de muerte a título de herencia o legado, o merced a ocupación, accesión o prescripción adquisitiva: si, en cualquier caso, es suya al momento de testar, el modo como la haya adquirido resulta completamente indiferente en el ámbito al que aquí nos referimos. Que la especie suya legada por un testador se haya hecho suya antes a título de legado, eso, pues, no determina alguna diferencia con el hecho de haberla adquirido por otro modo.

Concluimos, así, que un primer requisito del sublegado es que su disposición debe tener lugar en un testamento perfeccionado antes de la adquisición de la especie sublegada; lo cual implica que ella sea ajena.

5. La necesaria ajeneidad del objeto sublegado, sin embargo, no produce la nulidad de la disposición fulminada por la primera parte del artículo 1107 CC. ${ }^{16}$, porque

${ }^{16}$ Artículo 1107 CC.: "El legado de especie que no es del testador [...], es nulo [...]". 
ella resulta amparada por la excepción que esa misma norma formula a continuación: "[...] a menos que en el testamento aparezca que el testador sabia que la cosa no era suya [...]". En efecto, por definición el sublegado es de cosa ajena y el que lo dispone no puede menos que conocer la ajeneidad, que, por lo demás, normalmente aparecerá en el testamento mismo, como en la cláusula antes usada a modo de ejemplo: "Lego a Mevio el fundo Corneliano que Ticio me legó”. Quien testa así no puede ignorar, en ese momento, que el fundo Corneliano no le pertenece. Más aún, por eso es que dispone de la manera dicha.

6. El segundo requisito del sublegado es este: su disponente tiene que haber aceptado durante su vida el legado cuyo objeto él mismo había deducido en su asignación sublegataria. En otras palabras, al momento de morir el disponente del sublegado, el objeto de este ya tiene que haberse incorporado en su patrimonio; lo que implica la oportuna aceptación del legado principal. Por consiguiente, vale decir que el sublegado empieza por ser de cosa ajena y termina por recaer sobre cosa propia. Si tal no hubiera acaecido, el sublegado, que en su origen fue de cosa ajena, sigue siendo de cosa ajena al deferirse, y entonces se convierte en otra asignación, como veremos.

En tales condiciones, impiden poder producir sus efectos al sublegado las siguientes hipótesis: i) el repudio del legado deferido a quien dispuso el sublegado, por este mismo; ii) su incapacidad o indignidad para recibir el legado a él deferido; iii) su exheredación, si era legitimario del testador que le legó lo que el exheredado sublegó (artículo 1210 CC.); iv) la muerte del disponente del sublegado acaecida con anterioridad a la apertura de la sucesión del testador que legó algo en su favor, que él mismo había sublegado, porque entonces el primer legado ni siquiera alcanzó a ser deferido al disponente del sublegado.

En síntesis, pues, los dos requisitos del sublegado precedentemente analizados consienten decir que él recae sobre cosa ajena al ser dispuesto y sobre cosa propia al ser deferidos.

7. Cumplido este segundo requisito, tiene exactamente lugar lo señalado por el artículo 1108 CC.: "Si la cosa ajena legada pasó, antes de la muerte del testador, al dominio de este [...], se deberá el legado". Si en la disposición sustituimos "el legado" por "el sublegado", el asunto se comprende de inmediato; y resulta, así, que el sublegado puede producir el efecto normal de lo que después de todo no deja de ser, vale decir, de un legado. Él, aunque por su propia definición debió recaer en cosa ajena al ser dispuesto, empieza a ser de cosa propia desde que el testador adquirió en vida esa cosa; y tal es lo que le permite ser eficaz.

Por el contrario, si el disponente del sublegado no adquirió en vida la especie a él legada, entonces recibe aplicación la última parte del artículo 1107 CC., que, como diremos a final de este párrafo, implica la caducidad del sublegado y su sustitución por otros. Dice la norma: “[...], pues en estos casos se procederá como en el del inciso $1^{\circ}$ del artículo precedente”. La disposición supone el caso de un legado válido de cosa ajena al momento de testar que siguió en tal calidad al momento de deferirse la asignación (si en 
tal momento ya era del testador, se aplica, como vimos, el artículo 1108 CC. y se debe sin más el legado). Uno de "estos casos" de validez de los legados de cosa ajena previstos por el propio artículo 1107 CC. es que "en el testamento aparezca que el testador sabía que la cosa no era suya [...]". Tal es precisamente la hipótesis de un sublegado, que siempre es de cosa ajena, conocida como tal por el disponente del sublegado al momento de testar, como vimos. Así que, en final de cuentas, si el disponente del sublegado no hubo de tener adquirido a título de legado el objeto de aquel, al momento de deferirse su sublegado, por mandato de la disposición en examen debe aplicarse el inciso $1^{\circ}$ del artículo 1106; el cual dispone: "Podrá ordenar el testador que se adquiera una especie ajena para darla a alguna persona o para emplearla en algún objeto de beneficencia; y si el asignatario a quien se impone esta obligación no pudiere cumplirla porque el dueño de la especie rehusa enajenarla o pide por ella un precio excesivo, el dicho asignatario será solo obligado a dar en dinero el justo precio de la especie”. De acuerdo con la prescripción, aplicada a nuestro tema, el sublegado se convierte, por mandato de la ley, en otro tipo de legado, propiamente en uno de hacer, consistente en adquirir la especie sublegada, y de dar esa especie al sublegatario. Si el título de la adquisición haya de ser la compra (o la permuta, habría entender también) y el dueño de la especie se negare a venderla o pidiere un precio excesivo ( $u$ otra cosa de valor excesivo en permuta), se verifica una nueva conversión legal a un legado de dar dinero por un monto igual al del justo precio de la especie. Ahora bien, ninguno de los dos primeros legados convertidos, el de adquirir y dar la especie, ni el eventual tercero, de dar dinero, es un sublegado. En otras palabras, el sublegado caduca, como preanunciamos, y es reemplazado por legados legales ${ }^{17}$, ya que es la ley la que los dispone, en vía de conversión. Por lo demás, en el caso de los dos primeros, aunque el beneficiario de la asignación inicial recibe la especie que le había sido sublegada, no la recibe por causa de muerte, merced al legado, sino entre vivos, por tradición que le hace el obligado (normalmente el heredero) a adquirirla al dueño de tal especie y a darla al beneficiario. En el caso eventual del tercero, el beneficiario ni siquiera recibe la especie sublegada, sino dinero.

Se comprende ahora mejor porque es requisito segundo del sublegado, que su disponente haya adquirido en vida la especie de que se trata.

8. Cumple ahora examinar los esquemas bajo los cuales puede ser dispuesto un sublegado.

a) Ellos son tres.

i) Se lo puede, en efecto, disponer así: "Lego a Cayo el fundo Corneliano que Ticio me legó"; o bien: "Lego a Cayo el fundo que Ticio me legó".

ii) También es posible disponerlo bajo este esquema: "Si Ticio me legare el fundo Corneliano, se lo lego a Cayo"; o bien: "Si Ticio me legare un fundo, se lo lego a Cayo".

iii) Puede asimismo disponérselo de esta otra manera: "Si Ticio me ha legado el fundo Corneliano, se lo lego a Cayo"; o bien: "Si Ticio me ha legado un fundo, se lo lego a Cayo".

${ }^{17}$ Sobre la noción de "legado legal", véase: GUZMÁn BRITO (2008) pp. 60-64. 
En cada uno de los tres esquemas precedentes, como se ve, va prevista una fórmula alternativa para la determinación del objeto de la asignación, que queda representado por un fundo; el cual, en las primeras fórmula de cada esquema, es determinado por sus características genéricas y específicas ("fundo Corneliano") y además por una "indicación" ("que fue legado"); mientras que en las segundas fórmulas se omite la determinación del objeto merced a las dichas características ("un fundo"). En este caso, no por ello la disposición ha de tenerse por indeterminada y, consiguientemente, por no escrita, en los términos de la parte final del inciso $1^{\circ}$ del artículo 1066.

b) Para comprobarlo, menester es introducir en este punto una breve digresión hacia las reglas sentadas por aquel inciso en tema de determinación, el cual expresa: "Toda asignación deberá ser [...] de especies determinadas o que por las indicaciones del testamento puedan claramente determinarse". La asignación de una especie, o sea, el legado de tal, debe, pues, contener la determinación de la especie atribuida; lo cual es una aplicación de cierta regla general válida para todos los actos jurídicos (artículo 1461 CC.). El inciso $1^{\circ}$ de la norma citada da la posibilidad de que la exigida determinación de la especie sea operada por cualesquiera de estos dos métodos: por determinación directa ("especies determinadas") -llamémosla así-; o por "indicaciones" del testamento que puedan claramente determinar la especie. El primer método consiste en el señalamiento del género próximo al que pertenece la especie y de su diferencia específica (con frecuencia el nombre ${ }^{18}$ ); por ejemplo, si se lega el caballo llamado "Centella"; o solo de las diferencias específicas, elidiendo, pero subentendiendo el género, como cuando solo se dice "Centella". El segundo estriba en la descripción de algún atributo no esencial y accesorio que individualice la especie, como si al legarse un caballo pura sangre, en vez de designarlo por su nombre de "Centella", se lo indica solo por el hecho de haber ganado en la carrera "Derby de 2009". En la norma, estos métodos de determinación son alternativos; pero la alternativa no es exclusiva sino inclusiva, pues sus extremos pueden combinarse, como cuando se lega el caballo "Centella que ganó el Derby de 2009". Los juristas romanos denominaban demonstratio a eso que el Código llama "indicación"19; y esta palabra castellana, que afecta no tener sentido técnico y aparenta haber sido tomada del lenguaje usual, es, en realidad, una traducción bastante fiel de la latina, que sí tenía carácter técnico ${ }^{20}$, de modo que podemos considerarla técnica también.

La alternativa inclusiva de determinación que ofrece el inciso $1^{\circ}$ del artículo 1066 CC. es, pues, que la determinación del objeto legado pueda hacerse, bien por el señalamiento del género y la diferencia específica (o solo de esta), bien por una indicación, bien por el señalamiento del género y la diferencia (o solo de esta) y por una indicación. Si de acuerdo con la regla fundamental de interpretación del testamento (artículo 1069 inciso $2^{\circ}$ CC.), está clara la especie a la que la voluntad dispositiva del testador se

\footnotetext{
18 Pero véase la nota 25.

${ }^{19}$ La demonstratio puede referirse a una cosa, como se ha dicho, o a una persona; por ejemplo: "lego tal cosa al hijo de mi hermano"; para este último caso, el artículo 1057 CC. habla de "calidad".

20 Sobre la noción de demonstratio, véase una exposición general en GUZMÁN BRITO (2004) II, pp. 475477 y 695. Para detalles: VOCI (1963) II, pp. 850-856.
} 
dirigió, el error en la determinación directa, en la indicación o en ambas es irrelevante, siempre que resulte, empero, claro que aún sin el error hubiera tenido igualmente lugar la disposición, de modo de no ser motivante el error. Si, por ejemplo, con clara referencia volitiva al caballo "Centella", el testador escribió el caballo "Trueno", la disposición vale y se aplica al primero, aunque el testador erró en el nombre del corpus en que pensaba. Si con clara referencia al caballo que ganó la carrera Derby 2009, escribió el que "ganó en la carrera Derby 2008", también se aplica al primero, aunque haya errado en la demonstratio del corpus en que pensó; pero en el entendido de que, si el testador no hubiera incurrido en el error de confundir los nombres o los años, hubiera dispuesto igual; pues si en realidad pensó positivamente en el caballo "Centella" o en el que ganó en la carrera de 2008 y en cuanto y porque la ganó, aunque también haya ganado en la carrera del año 2009, el error de creer que había ganado en el 2008 hace que la disposición se tenga por no escrita; si, de nuevo, la referencia es clara al caballo "Centella" que ganó la carrera Derby 2009, pero escribió el "caballo Trueno que ganó la carrera Derby 2008", la disposición también se aplica al primero; nuevamente en el entendido de no haber habido un error motivante. Por consiguiente, el error en el nombre (llamado error in nomine en la tradición romanística) o el error en la demonstratio (falsa demonstratio), estando claro en qué cosa o corpus pensó el testador, no afectan su asignación. En el Código, esta regla está enunciada solo para el error en el nomen o en la demonstratio concerniente a personas, que el artículo 1057 CC. llama "calidad"21; pero es la misma que rige en materia de "indicación" de cosas. La ausencia de error motivante deriva, para nombres e indicaciones, del artículo 1058 CC. ${ }^{22}$. Los juristas romanos sostenían, como regla, que "falsa demonstratio non nocet" ("una falsa indicación no daña", se entiende que a la asignación) ${ }^{23}$; y la misma idea, por cierto, empleaban para el error in nomine $e^{24}$. El tema presenta otros aspectos, pero lo dicho es bastante para nuestro actual propósito.

c) Ahora bien, cuando en cada uno de los tres esquemas de sublegado antes ofrecidos aparece la mención del "fundo Corneliano", con ello queda representada la forma de determinación que hemos llamado "directa", que en tales casos consiste en el señalamiento del nomen ${ }^{25}$. La mención de "ser legado el fundo", en cambio, en algunos

${ }^{21}$ Artículo 1057 CC.: "El error en el nombre o calidad del asignatario no vicia la disposición, si no hubiere duda acerca de la persona".

22 Artículo 1058 CC.: "La asignación que pareciere motivada por un error de hecho, de manera que sea claro que sin este error no hubiera tenido lugar, se tendrá por no escrita".

${ }^{23}$ La regla, como generalmente válida para la institución de heredero, legados y fideicomisos aparece enunciada en Dig. 35,1,33 pr. Véasela también en: Tit. Ulp. 24,19; Inst. Iust. 2,20,30; Dig. 28,5,49,3; $30,75,1-2 ; 30,108,8 ; 32,35,1-2 ; 32,102$ pr.; 33,4,1,8; 34,2,10; 35,1,17 pr.; 35,1,33 pr.; 35,1,34; $35,1,40,4 ; 35,1,72,8$; Cod. Iust. 6,23,4; 6,37,7,1.

${ }^{24}$ Véase Inst. Iust. 2,20,29; Dig. 5,1,80; 28,1,21,1; 30,4 pr.; 34,5,28; 35,1,17,1; 35,1,19; 35,1,27; 35,1,21; 40,5,54; Cod. Iust. 6,23,4; 6,37,7,1.

${ }^{25}$ Como es frecuente en los predios rústicos (haciendas, fundos y quintas). Mas puede ser por la población, calle y número de localización (y, en su caso, del número que tiene un departamento y de nuevo por el nombre del edificio al que pertenece), por sus deslindes, por la foja y número de su inscripción en el Registro de Propiedad, por el título de adquisición y su fecha o su causahabiente ("el fundo que compré en tal fecha" o "que compré a Ticio"), por la situación jurídica ("la casa que tengo dada en usufructo o en arrendamiento a Ticio"), etcétera. 
casos solo corresponde a una "indicación" o demonstratio y en otros da contenido a otra figura que puede funcionar como "indicación", según veremos.

Debemos ahora examinar el alcance de cada uno de estos esquemas de formulación.

9. Desde luego, observemos el sublegado del tipo i): "Lego a Cayo el fundo Corneliano que Ticio me legó"; o bien: "Lego a Cayo el fundo que Ticio me legó". Las dos posibilidades de formulación que admite el esquema contienen, como puede verse, un sublegado puro y simple. Él es el adecuado en caso que su disponente se encuentre seguro, al momento de disponerlo, que el fundo Corneliano le fue legado por Ticio en su testamento. La mención de haber sido legado el fundo es común a las dos formulaciones del esquema en actual examen, porque en ambos casos cumple una función anexa de dar carácter expreso de sublegado a la asignación. Pero a veces es "indicación” propiamente tal, en rol determinador; y a veces no lo es y adquiere carácter esencial de la asignación. El destino de esta, empero, depende de qué haya ocurrido en la realidad, según los diferentes eventos que consideraremos.

a) En la primera formulación, el objeto está conjuntamente determinado por su género y diferencia específica ("fundo Corneliano", o sea, por el nomen); y por la circunstancia expresada en la dicción "que Ticio me legó", que es, por ende, una "indicación”. Según la regla del artículo 1066 inciso $1^{\circ}$ CC. la determinación es legalmente correcta por cualesquiera de ambos métodos, de lo que se deduce que, siendo claro en qué objeto pensó el testador, y no habiendo este sufrido un error determinante, si una es errónea, pero verdadera la otra, o ambas erróneas, el legado mantiene su determinación y, por ende, su validez. Pero el destino del sublegado está determinado por lo que haya acaecido en los hechos.

Porque, en efecto, al momento de abrirse el testamento que contiene este esquema de sublegado, y i) en el patrimonio sucesorio existe un fundo llamado Corneliano porque había sido legado por Ticio al causante, antes de testar este, y aceptado por el mismo, entonces el sublegado está en regla de modo de deber entregarse el fundo al legatario. Cuando ii) no existe en la masa un fundo que se llame Corneliano ni que hubiera sido legado por Ticio al causante, del cual fundo, empero, es dueño Ticio (o su heredero o algún legatario suyo lo es), la asignación que empezó como un sublegado se convierte en legado ordinario de cosa ajena, y se resuelve en algunas de las alternativas prevista por el artículo 1106 inciso $1^{\circ}$ CC.; así que el obligado a cumplir la primitiva asignación debe adquirir el fundo de su dueño y darlo al asignatario o, no siendo ello posible por las razones que dice la norma, dar su justo precio a este.

b) Por cierto, puede acaecer que en la sucesión del que dispuso el sublegado exista un fundo que se llama Corneliano, pero que no le había sido legado por Ticio; o bien un fundo que no se llama Corneliano y que sí lo había sido. Ahora bien, en el primer caso, o hubo error in corpore, porque el fundo existente en la sucesión, que también se llama Corneliano, es otro que el pensado por el testador al sublegar, y entonces el sublegado no vale; o no hubo tal error y el fundo en que el testador pensó llegó a su patrimonio a un título diferente al legado de Ticio, caso este que trataremos en el número 14, porque 
es común a todos los esquemas. El segundo caso también lo trataremos aparte, pero seguidamente.

c) Dijimos que este tipo de legado se adecua al caso en que el testador se halle seguro, al momento de disponerlo, que el fundo Corneliano le fue legado por Ticio en su testamento. Pero, naturalmente, pudo haberse equivocado sobre el punto bajo dos respectos:

i) Si al momento de testar el disponente del sublegado, el fundo no le había sido legado, pero lo fue después y lo aceptó (aunque, por cierto, antes de morir). En principio, el hecho resulta indiferente, atendido que, aun así, continúa en aplicación el artículo 1108 CC.: aquel objeto fue sublegado por él como ajeno y pasó a su dominio antes de morir: en tal caso se debe el legado, dice aquella norma. La mención de "haber sido legado" el fundo al momento de testar es una "indicación” que, aunque falsa, no daña, pues, la asignación; y se está a la determinación del nomen ("fundo Corneliano"). Pero si aparece claro que el testador pensó en ese fundo en cuanto ya legado al momento de testar y solo bajo esa circunstancia, de manera que, de haber sabido que no le había sido legado, no lo hubiera sublegado, eso quiere decir que la mención dicha no es "indicación", sino un elemento añadido con carácter esencial por el testador; y entonces el sublegado se tiene por no escrito (artículo 1058 CC.).

ii) Cuando, de hecho, el fundo Corneliano sublegado por el testador, no le fue legado antes ni después de disponer; pero resulta haberle sido legada otra cosa con anterioridad o posterioridad (y cuya asignación acepta), como si el testador dice: "Lego a Cayo el fundo Corneliano que Ticio me legó”; pero Ticio jamás legó el dicho fundo al testador, aunque le legó el fundo Capeno. El destino de esta asignación, que es una de las enunciadas en la letra b) precedente, depende de la ocurrencia o no de algunos factores. Si la referencia a haber sido legado el fundo Corneliano se haya tratado de un error in nomine, el legado vale sobre el fundo Capeno efectivamente legado: el testador, en efecto, confundió un nombre por otro, en circunstancia de aparecer claro que se refería al corpus que le había sido legado, aunque se llamara Capeno. Si, en cambio, no hubo tal error y el testador quiso referirse no a otro fundo que al Corneliano (cuya ajeneidad, por cierto, conocía), en el entendido que igualmente lo hubiera legado de haber sabido que no le había sido legado a él, la asignación sublegataria vale como legado ordinario de cosa ajena y se está a lo dispuesto por el artículo 1106 inciso $1^{\circ}$ CC., según lo dicho antes; pero cuando se pruebe que el testador no hubiera asignado el fundo, de haber conocido la circunstancia de no haberle sido legado, dicha asignación no vale, de acuerdo con el artículo 1058 CC.

d) En el evento de que la formulación del sublegado sea con la segunda alternativa: "Lego a Cayo el fundo que Ticio me legó", la determinación del objeto aparece expresada solo por la "indicación" de haber sido legado el fundo, y también vale, aplicada a cualquier fundo que Ticio haya legado al disponente del sublegado, llámese como se llame; a menos de probarse que aquel pensó en un fundo determinado y el que le llegó merced al legado de Ticio fue otro, caso en el cual hay que estar a las diferentes posibilidades tratadas en el número ii) inmediatamente precedente, en lo aplicable, porque el caso se convierte a la hipótesis expuesta ahí. 
10. Comparece ahora el sublegado del tipo ii): "Si Ticio me legare el fundo Corneliano, se lo lego a Cayo"; o bien: "Si Ticio me legare un fundo, se lo lego a Cayo". El sublegado, en ambas formulaciones, contiene una condición. Este esquema es el apropiado para el caso en que el disponente del sublegado no esté seguro, en el momento de testar, que el fundo le ha sido legado por alguien (Ticio) o, al menos, para cuando en ese momento ignore si le fue legado por él; en ambos casos, con la esperanza de que le sea legado en un tiempo posterior. Entonces, en la manera dicha, lega el objeto esperado a un tercero, para el evento de que efectivamente le sea legado a él.

En la primera formulación del esquema, la determinación se hace en forma directa ("el fundo Corneliano" al cual se refiere el pronombre "lo" en la dicción "se lo"). La mención concerniente a que el fundo haya de ser legado, en rigor, no es pura "indicación", porque ella da contenido a una condición; con todo, también cumple el rol de "indicación", pues la disposición equivale a que el testador hubiera dicho: "Si Ticio me legare el fundo Corneliano, lego a Cayo el fundo Corneliano que Ticio me haya de legar”. Además, opera para dar carácter expreso de sublegado a la asignación.

$\mathrm{Al}$ abrirse la sucesión del primer testador (Ticio), puede acaecer que efectivamente el fundo aparezca legado al disponente del sublegado o que no le aparezca legado. En el primer caso, la condición se cumplió; y ahora es necesario que el disponente del sublegado acepte el legado principal a él deferido, con lo cual el fundo ingresa en su patrimonio. Cuando él muera, a su vez, y se abra su propia sucesión, el sublegado produce su efecto y el sublegatario adquirirá el objeto, si acepta a su turno la asignación. En el segundo caso, al abrirse la sucesión del disponente del sublegado, se comprobará que la condición del sublegado había fallado y este, sin más, no produce efecto alguno de acuerdo con las reglas generales sobre condición.

Podría pensarse, sin embargo, en su conversión en los términos del artículo 1106 inciso $1^{\circ}$ CC., porque, después de todo, el sublegado es de cosa ajena también al momento de deferirse y su disponente supo, cuando lo dispuso, que el fundo le era ajeno (artículo 1107 CC.). Vale decir, podría pensarse en que se produjese la misma situación que hemos examinado a propósito del sublegado del tipo precedente, en la alternativa ii) de la letra a) del número 9. Pero no es así: en tal tipo de sublegado, la referencia a ser legado el fundo es solo una "indicación" individualizadora; en el tipo ahora analizado, en cambio, la referencia es primariamente condición; y aunque también sirve de "indicación", el anterior carácter prevalece. En tales circunstancias, al no haberse cumplido la condición, el sublegado no puede producir efecto.

Hemos dicho que el sublegado condicional en examen es el apropiado cuando el subtestador sabe, en el momento de testar, que el fundo no le ha sido legado, o bien si duda o ignora si lo ha sido. Naturalmente, puede acaecer que de hecho le haya sido legado a ese momento. En tal caso, la condición que el subtestador formuló en la creencia de ser verdadera condición de futuro incierto, consiste en un hecho que ya se ha realizado, y entonces recibe aplicación el artículo 1071 CC.: "Si la condición que se impone como para tiempo futuro, consiste en un hecho que se ha realizado en vida del testador [...]; y si el testador no lo supo, se mirará la condición como cumplida [...]". Teniendo presente que la cláusula "y si el testador no lo supo" atañe a que el testador no 
haya sabido que el hecho por él mirado como futuro ya había tenido lugar, entonces el sublegado es eficaz.

11. Se presenta, en fin, el sublegado del tipo iii): "Si Ticio me ha legado el fundo Corneliano, se lo lego a Cayo"; o bien "Si Ticio me ha legado un fundo, se lo lego a Cayo" aparece dispuesto bajo condición impropia, por consistir en un hecho del pasado. Tal asignación se acomoda bien al caso en que el disponente del sublegado crea, en el momento de testar, que le ha sido legado el fundo; pero funciona igual si él sabía que le había sido legado, y entonces se aproxima al tipo i), revisado en el número 9.

En la primera formulación, la determinación del objeto se hace de manera directa ("el fundo Corneliano" al cual se refiere el pronombre "lo" en la dicción "se lo"). La mención concerniente a que el fundo haya de ser legado nuevamente no es pura "indicación", porque da sustancia a una condición, aunque sea impropia; pero igualmente cumple el papel de "indicación”, ya que la asignación es equivalente a que el testador la hubiera dispuesto así: "Si Ticio me ha legado el fundo Corneliano, lego a Cayo el fundo Corneliano que Ticio me hubiera legado". Asimismo, cumple la función de hacer expreso al sublegado.

La figura exige la aplicación del inciso $1^{\circ}$ del artículo 1071 CC.: "La condición que consiste en un hecho presente o pasado, no suspende el cumplimiento de la disposición. Si existe o ha existido, se mira como no escrita; si no existe o no ha existido, no vale la disposición. [inciso $2^{\circ}$ ] Lo pasado, presente o futuro se entenderá con relación al momento de testar, a menos que se exprese otra cosa". Por consiguiente, si, al momento de testar el disponente del sublegado, existía dispuesto un legado de Ticio sobre el fundo Corneliano a su favor, la condición de este se mira como no escrita, vale decir, como puro y simple el sublegado, que entonces queda reconducido como si hubiera sido dispuesto bajo la forma estudiada en el número 9 y la mención de haber sido legado el fundo ahora vale como "indicación" puramente determinadora del objeto. Si, en el mismo momento, no había un legado de Ticio sobre el fundo a favor del disponente del sublegado, este no vale entonces y nada recibe el sublegatario; así que ni siquiera puede tener lugar la conversión del legado previsto, merced al artículo 1107 CC. por su artículo 1106 inciso $1^{\circ}$, como ordinario de cosa ajena, porque por sobre el rol de "indicación” que tiene la referencia a haber sido legado el fundo prima el de condición impropia que ella tuvo en la asignación. Tampoco, pues, cabe pensar en la conversión a los términos del artículo 1106 inciso $1^{\circ} \mathrm{CC}$, porque es claro que el testador solo quiso sublegar si el fundo le fue legado por Ticio y que, como ignoraba si tal había acaecido, dispuso en la forma en que lo hizo; de haber sabido que el fundo no le había sido legado, no habría dispuesto; de donde la entera congruencia que, en el caso de no haber habido legado, se anule la disposición.

12. Puede ocurrir que alguien legue una cosa ajena, sabiendo que es ajena (porque si no lo sabe, el legado es nulo, según el artículo 1107 CC.), pero ignorando que le fue legada y sin la previsión de haberlo sido o haber de serle legada; y que, sin embargo, de hecho le hubiera sido legada antes y el beneficiario adquiera en vida lo legado. La 
hipótesis no ofrece dificultad alguna, porque queda regida de lleno y sin más por el artículo 1108 CC.: "Si la cosa ajena legada pasó, antes de la muerte del testador, al dominio de este [...], se deberá el legado". Pero el tema es saber si tal constituye un sublegado del tipo iii) tratado en el número 11 . De estarse a una opinión positiva, se trataría de una suerte de sublegado como por casualidad o que, sin saberlo el testador, resultó ser tal. La opinión negativa tendría que fundarse en la exigencia de que, para haber sublegado, su disponente debe actuar sobre la base de haberle sido legada la cosa o prever, condicionalmente, que ha de serlo. Se trataría, pues, de una suerte de requisito subjetivo de la figura.

Ahora bien, como los efectos de un sublegado conscientemente dispuesto como tal y de un legado de cosa ajena que después resultó adquirida por legado, aunque el testador no lo supo al disponer (sin perjuicio de tener que conocer la ajeneidad de la cosa, so pena de nulidad de la asignación), son los mismos, no vale la pena separar demasiado ambas figuras. Así que podemos hablar en este caso de sublegado precisamente "casual".

13. También puede ocurrir que alguien legue una cosa ajena, sabiendo que es ajena (porque si no lo sabe, el legado es nulo, según el artículo 1107 CC.), pero ignorando que le fue legada y sin la previsión de que lo haya sido o haya de serle legada; y que, de hecho, no le hubiera sido legada entonces; pero que le fue legada después y el beneficiario adquiera en vida lo legado. La hipótesis tampoco ofrece dificultad, pues también entre en la órbita del artículo 1108 CC. Pero asimismo el tema es saber si ella constituye un sublegado del tipo i) tratado en la letra a) del número 9, como alternativa i). En contra está el hecho de que, al momento de ser dispuesta la asignación, ella no constituyó, sin más, un sublegado, porque el objeto no había sido legado al disponente; no se trató, pues, del legado de lo legado, que es como la esencia de la figura. Esto parece suficiente. Pero a favor está el hecho que, al abrirse la sucesión del disponente, se hallará la cosa que había sido legada como ajena al testar y que ahora pertenece a la sucesión; así que se deberá aplicar el artículo 1108 CC. sin más; lo cual equivale a un sublegado del tipo i), tratado en la letra a) del número 9. Esta igualdad de efectos aconsejaría ver un sublegado en la figura, que entonces podría ser denominado "impropio", porque no debe dejarse de lado la precedente observación en contra, que hace ver la indiscutible inexistencia de un sublegado al momento de testar. Como, empero, termina por ser como un sublegado, también se lo podría denominar "sobrevenido".

14. Asimismo, es posible que alguien disponga un verdadero sublegado, vale decir, con la previsión de haberle sido legado a él su objeto, o de habérsele de legar en el futuro, y que ese objeto se haga suyo antes de morir, pero a otro título que el de legado. Aparentemente sería necesario también aplicar el artículo 1108 CC. Pero en realidad no es así más que en un caso.

a) Si el sublegado fue del tipo i) según la formulación: "Lego a Cayo el fundo Corneliano que Ticio me legó”, debe aplicarse el artículo 1108 CC., sin prestar atención 
al hecho de que el fundo Corneliano que exista en la sucesión no fue legado al causante por Ticio, pues aquel lo adquirió por cualquier otro modo. Ello es debido a que, como quedó dicho en su momento, la cláusula "que Ticio me legó" funciona aquí como “indicación”. Si resultó falsa, como es nuestra hipótesis, entonces es suficiente la determinación por el género próximo y diferencia específica del objeto: "el fundo Corneliano”, que deberá ser, pues, entregada al legatario merced al artículo 1108 CC. A menos que se pruebe que la mención de haber sido legado el fundo por Ticio fue esencial para la disposición del testador, y no mera "indicación", de modo que, de haber sabido que el fundo no le había sido legado por Ticio, no lo hubiera sublegado, caso en el cual es nula la asignación (artículo 1058 CC.).

Si la formulación fue: "Lego a Cayo el fundo que Ticio me legó", ningún fundo que el disponente del sublegado haya adquirido a un título diferente que el del legado de Ticio cumple con la determinación bajo forma de "indicación” hecha en el sublegado, y cabe aplicar el inciso $3^{\circ}$ del artículo 1116 CC.: "Si se legó una cosa de aquellas cuyo valor no tiene limites, como una casa, una hacienda de campo, y no existe ninguna del mismo género entre los bienes del testador, nada se deberá [...]"; así que el legado resulta, no nulo, sino ineficaz.

b) Cuando el sublegado haya sido del tipo ii), según la formulación: "Si Ticio me legare el fundo Corneliano, se lo lego a Cayo", entonces quiere decir que la condición de la asignación falló, y esto es suficiente para negarle eficacia de acuerdo con las reglas generales que rigen las asignaciones bajo condición. De hecho, el testador quiso que el fundo llegare a Ticio solo si es que él se hubiera hecho dueño del fundo en virtud de un legado de Cayo y fue tal lo que formalizó merced al establecimiento de la condición; incumplida la cual, se vulneraría su voluntad si se cumple el sublegado; ni siquiera bajo pretexto del artículo 1108 CC., que rige para las disposiciones puras o condicionales con condición cumplida. Lo propio cabe decir para el sublegado formulado como: "Si Ticio me legare un fundo, se lo lego a Cayo".

c) La aplicación del artículo 1071 CC. a la hipótesis de un sublegado del tipo iii) bajo la formulación: "Si Ticio me ha legado el fundo Corneliano, se lo lego a Cayo", conduce a negarle valor, pues el hecho pasado deducido en él no existía al momento de disponérselo: si el disponente del sublegado adquirió el fundo dicho a otro título -que es nuestra actual hipótesis-, ello tuvo que acaecer después de testar, pues no es comprensible que ya lo tuviera adquirido antes y luego hubiera testado como lo hizo. El testador (que no sabía si el fundo le había sido legado o no, y por ello fue que dispuso en la forma dicha) quiso que el fundo llegare a Cayo solo si le había sido legado a él por Ticio; así que, de haber sabido al disponer el sublegado que el fundo no le había sido legado, no lo habría dispuesto. Es, pues, del todo lógico que, como de hecho no le había sido legado, la ley impida la validez de su propio sublegado del mismo fundo.

15. Todavía se presenta un tema por dilucidar. Concierne al interés práctico satisfecho por el sublegado.

a) ¿Qué interés puede, en efecto, tener un testador en legar una cosa ajena que le ha sido o haya de serle legada? El comienzo de la respuesta se encuentra en algún 
carácter ofrecido por la cosa misma, que induzca al testador a asegurarla para alguien después de sus días. Ahora bien, ello vale no exclusivamente para el sublegado, sino para cualquier legado de cosa ajena a sabiendas, es decir, aunque después se adquiera a un título diferente al del legado por el testador. La respuesta, por ende, queda más completa al atender precisamente a la especialidad de la adquisición de la cosa ajena legada prevista por el testador para él; precisamente a título de legado. Así que el acento ahora se extiende desde el carácter peculiar de la cosa a algún carácter peculiar de sus dueños. Tal radica en el parentesco que liga a los sucesivos previstos dueños. Se trata en síntesis de cosas que han estado en el ámbito de una línea de parientes y que se desea que sigan estando ahí. El sublegado, por consiguiente, cumple la función de conservar una cosa en cierta familia. Supóngase una línea de cuatro generaciones vivas: un bisabuelo es dueño de cierta cosa especialmente importante para la tradición familiar. Si aquel asegura a su hijo que habrá de legarle (dentro de las posibilidades permitidas por el sistema de libertad restringida de testar que rige en Chile) la cosa de que se trata, para que dicho hijo, a su vez, la legue a su propio hijo, el nieto, quien debería legarla al suyo, el biznieto, entonces el asunto puede plantearse así: que el hijo legue el objeto de que se trata al suyo, si su padre se lo ha legado o haya de legárselo a él; y que ese hijo, o sea, el nieto, a su vez, legue el mismo objeto a su propio hijo, el bisnieto, si su padre se lo ha legado o haya de legárselo a él. En tal caso, con solo dos testamentos contemporáneos, la propiedad del objeto queda asegurada para tres generaciones, pues la cosa pasará del actual dueño, el bisabuelo, al abuelo, al nieto y al bisnieto, quien, a su turno, podría repetir a operación con sus propios descendientes.

La función del sublegado es, pues, la de vincular una cosa a una línea de parientes; aunque nada obsta a que lo propio se haga en una línea de no parientes, si bien en tal caso la posibilidad de un interés práctico en hacer la vinculación sea más débil. De donde se deduce la conveniencia de mantener la distinción, aunque sea nominal, del sublegado y de aquellos que hemos denominado "casual" e "impropio", porque la imprevisión del disponente en estos casos, sobre que el objeto asignado le haya sido o haya de serle legado es señal de que su interés al legar era el general que puede tener cualquier testador que dispone sobre cierta cosa ajena a sabiendas.

b) Por cierto, esta vinculación nada tiene que ver con las conocidas por el Derecho antiguo, del tipo de los mayorazgos y otras, porque no se trata de una vinculación legal ni forzosa, sino meramente voluntaria y tanto, que depende de que cada persona involucrada quiera verdaderamente hacer el legado que corresponda, el cual, por otra parte, una vez dispuesto, puede ser revocado expresamente como todos los legados de modo de interrumpir la esperada vinculación; sin hacer caudal de que cada nuevo legatario puede, sin restricciones, enajenar el objeto, con lo cual también revoca el legado, a tenor del artículo 1135 inciso $2^{\circ}$ CC.; y sin atender que si se añadiere al sublegado una condición de no enajenar el objeto de que se trate, si esa condición solo está dirigida a asegurar la eficacia práctica de la vinculación, se debe tener por no escrita en cuanto al punto de que la enajenación no compromete ningún derecho de los sublegatarios, siendo, como es, que nadie designado legatario en un testamento tiene derecho alguno a adquirir el legado mientras no haya muerto el testador (artículo 1226 CC.); así 
que no podría alegarse que la enajenación del objeto por alguno de sus actuales dueños compromete el derecho de los sucesivos sublegatarios.

16. Subsiste un último punto que aclarar: si el sublegado implica alguna agresión a la libertad de hacer testamento o de no hacerlo o de hacerlo como se quiera (dentro de los límites legales). Si entre los miembros de una línea parental hay algún acuerdo en orden a instituir sucesivos sublegados, eso no es menos válido que el acuerdo de dos en orden a hacer testamento recíproco; porque, como en este, aquel no obliga a su cumplimiento ni su incumplimiento afecta la validez de los testamentos otorgados, los cuales, por lo demás, pueden ser libremente objetos de revocación una vez otorgados.

Pero, en fin, cabe diagnosticar si el sublegado constituye una disposición captatoria, fulminada con invalidez por el inciso $1^{\circ}$ del artículo 1049 CC. Claramente no, si estamos a la definición de aquella ofrecida por el inciso $2^{\circ}$ del mismo artículo: "Se entenderán por tales aquellas en que el testador asigna alguna parte de sus bienes a condición que el asignatario le deje por testamento alguna parte de los suyos”. En el sublegado, su disponente puede asignar algo bajo condición, pero esta no va dirigida a conseguir que el sublegatario le asigne algo suyo en su propio testamento, a su vez. La condición va dirigida a ganar el objeto dicho disponente a partir del testamento de otro, que no es su asignatario; sin hacer ningún caudal de que en el sublegado no se asigna "alguna parte de sus bienes", como reza la definición, sino una cosa ajena. De esta manera, no hay cómo ver una disposición captatoria en un sublegado.

\section{BIBLIOGRAFÍA}

Abeliuk ManaseVich, René (1993): Las obligaciones (Santiago, Editorial Jurídica de Chile, $3^{a}$ edición).

BELlO, Andrés (1981): Instituciones de Derecho romano [1843, reimpresión en Obras completas de Andrés Bello (Caracas, La Casa de Bello), XVII: Derecho romano].

Claro Solar, Luis (1982), Explicaciones de Derecho civil chileno y comparado (1944, reimpresión Santiago, Editorial Jurídica de Chile, 1982) XVII: De la sucesión por causa de muerte), $\mathrm{V}$.

Codex Iustinianus (ed. Krüger).

Código Civil de la República de Chile (2008) (Santiago, Editorial Jurídica de Chile, $18^{\mathrm{a}}$ edición).

Código de Comercio de la República de Chile (2008) (Santiago, Editorial Jurídica de Chile, 17 a edición).

Domínguez Benavente, Ramón y Domínguez Águila, Ramón (1998): Derecho sucesorio (Santiago, Editorial Jurídica de Chile, 2a edición).

ElorRiaga De BONIS, Fabián (2005): Derecho sucesorio (Santiago, LexisNexis) 778 pp. GUZMÁN BRITO, Alejandro (2004): Derecho privado romano (Santiago, Editorial Jurídica de Chile, $1^{\text {a }}$ edición, $4^{\mathrm{a}}$ reimpresión).

GUZMÁN BRITO, Alejandro (2008): "El concepto de legado en el Derecho civil chileno", Revista de Derecho (Universidad Austral de Chile) vol. 21 No 2: pp. 53-84. 
Iustiniani Digesta (ed. Mommsen).

Iustiniani Institutiones (ed. Krüger).

LÓpez SAnta María, Jorge (2005): Los contratos. Parte general (Santiago, Editorial Jurídica de Chile, $4^{\text {a }}$ edición).

Meza BARros, Ramón (2007): Manual de la sucesión por causa de muerte y donaciones entre vivos (Santiago, Editorial Jurídica de Chile, 8a edición) 535 pp.

Rodríguez Grez, Pablo (2002): Instituciones de Derecho sucesorio (Santiago, Editorial Jurídica de Chile, 2a edición).

Somarriva Undurraga, Manuel (2004): Derecho sucesorio (Santiago, Editorial Jurídica de Chile, $7^{\text {a }}$ edición).

Tituli ex corpore Ulpiani (ed. Baviera).

VOCI, Pasquale (1963): Diritto ereditario romano (Milano, Giuffrè, 2a edición). 